

\title{
APLICAÇÃO DO QGIS COMO FERRAMENTA PARA O PREENCHIMENTO DO CADASTRO AMBIENTAL RURAL - CAR NO MUNICÍPIO DE BARCARENA, NO ESTADO DO PARÁ
}

\author{
Apresentação: Comunicação Oral \\ Valto Coelho Santana Junior ${ }^{1}$; Jandson José do Vale Guimarães²; Tatiana Pará \\ Monteiro de Freitas ${ }^{3}$
}

DOI: https://doi.org/10.31692/2526-7701.IVCOINTERPDVAgro.2019.0047

\begin{abstract}
Resumo
Atualmente, considera-se o Novo Código Florestal como um pilar criado para contornar diversas questões ambientais, permitindo a regularização das propriedades que estão em contratempo com a lei. Assim, para que isso ocorra, criou-se programas e ferramentas para articular os trâmites da regularização ambiental, tendo o Cadastro Ambiental Rural (CAR) como um registro dos imóveis rurais para fins de controle, monitoramento ambiental, facilitação dos processos de licenciamento das atividades rurais, gestão integrada dos territórios, além do acompanhamento dos ativos ambientais das propriedades. O cadastramento também vai proporcionar a obtenção aos créditos, contratação de seguro agrícola, redução nas taxas de impostos, inclusive para insumos e equipamentos de forma geral. Neste trabalho, para a realização do CAR do Imóvel, usou-se ferramentas do software (QGIS), com base nos Sistemas de Informações Geográficas (SIG) que subsidia o processo de regularização dos territórios, o cadastro das propriedades rurais e nos limites definidores. A partir disso, servem de base para apresentar as discussões teóricas, os resultados, e as considerações finais. Os resultados obtidos foram, em grande parte, satisfatórios, já que permitiram a realização do CAR de forma mais precisa e completa, afim de todas as informações do imóvel sejam de fato apresentadas. No entanto, um importante questionamento levantado na pesquisa remete aos impasses gerados pelas questões de sobreposições territoriais, as quais alcançam mais de 14 milhões de hectares sobrepostos, no estado do Pará. Apesar disso, o trabalho mostrou-se eficiente quanto a utilização do programa e referente a eficácia do Cadastro Ambiental Rural quando manipulado por pessoas instruídas.
\end{abstract}

Palavras-Chave: Novo Código Florestal, Cadastro Ambiental Rural, Área de Proteção

\footnotetext{
${ }^{1}$ Especialista em Georreferenciamento de Imóveis Rurais, Faculdade Ieducare, walto_jr2008@hotmail.com

${ }^{2}$ Graduando em Agronomia, Instituto Federal de Educação, Ciência e Tecnologia do Pará, campus Castanhal, guimaraesjandson@gmail.com

${ }^{3}$ Especialista em Geotecnologias: Geoprocessamento e Sensoriamento Remoto, Instituto Federal de Educação,

Ciência e Tecnologia do Pará, campus Castanhal, tatiana.para@ifpa.edu.br
} 
permanente, Regularização Ambiental, Software QGIS

\section{Introdução}

O município de Barcarena é uma região de importância socioeconômica e ambiental, mas que apresenta diversos conflitos relacionados a sua condição industrial (NASCIMENTO, 2012). Conforme Coelho (2004), esse fator foi condicionado devido às crescentes demandas de insumos minerais, e pelas políticas nacional e estadual de incentivo às exportações.

Frente a essa circunstância, houve a necessidade de estabelecer-se o Cadastro Ambiental Rural (CAR), o qual trata-se do registro de imóveis rurais para fins de controle, monitoramento ambiental, facilitação dos processos de licenciamento das atividades rurais, gestão integrada dos territórios e acompanhamento dos ativos ambientais das propriedades (MORETTI et al., 2015a). Para auxiliar no processo, toma-se como base as técnicas geotecnológicas, com ênfase no Sensoriamento Remoto, o qual através de resoluções espaciais, geométricas, espectrais e radiométricas, permite um eficiente monitoramento geral da localidade estudada (ANTUNES, 2014).

Por meio disso, entende-se o funcionamento do CAR, de acordo com Moretti et al. (2015) por um sistema eletrônico de identificação georreferenciada dos imóveis rurais, delimitando com precisão as Áreas de Preservação Permanente (APP), as Reservas Legais (RL), as áreas passíveis de uso alternativo do solo, além da hidrografia e dos remanescentes de vegetação nativa localizados no interior dos imóveis (MORETTI et al, 2015b).

De acordo com Teixeira Neto (2006), esse cadastro proporciona diversos benefícios relacionados ao acesso à emissão das Cotas de Reserva Ambiental e aos benefícios previstos nos Programas de Regularização Ambiental e de Apoio e Incentivo à Preservação e Recuperação do Meio Ambiente. Dentre esses, cita-se à possibilidade de regularização das APP e/ou Reserva Legal, suspensão de sanções, obtenção de crédito agrícola, contratação do seguro agrícola, dedução das Áreas de Preservação Permanente, de Reserva Legal e de uso restrito, além das linhas de financiamento e isenção de impostos para os principais insumos e equipamentos.

A utilização do software QGIS explica-se por meio da sua interface simplificada e da maior facilidade de manipulação das diversas ferramentas disponíveis, além de ser um programa totalmente gratuito, (OLIANI et al., 2012).

Há de se considerar que a ordenação dos dados obtidos por meio das geotecnologias, é possibilitada por meio do Sistema de Informação Geográfica (SIG). Segundo Rosa (2013), um 
SIG pode ser definido como um sistema destinado à aquisição, armazenamento, manipulação, análise, simulação, modelagem e apresentação de dados referidos espacialmente na superfície terrestre, integrando diversas tecnologias.

Dada a possibilidade de realizar mapeamentos georreferenciados e o consequente monitoramento das áreas rurais, por meio da utilização do aparato SIG (CAMARA; DAVIS; 1996), pode-se evitar ou amenizar diversos problemas intrínsecos ao meio rural, tanto de cunho territorial e ambiental, como social, uma vez que ambos estão relacionados ao tratar-se de delimitação.

Em detrimento disso, o presente trabalho deteve-se às coletas de informações a respeito das aplicações do software livre QGIS para elaboração do CAR, no município de Capanema no estado do Pará, tendo como referência o ministério do meio ambiente responsável pela regularização ambiental das propriedades rurais.

\section{Fundamentação Teórica}

O grande enfoque dado para a cidade de Barcarena está relacionado com as vastas transformações expressivas em função da instalação de grandes projetos destinados a transformação do alumínio e caulim, pelas as empresas ALBRAS, ALUNORTE, ALUBAR e PARAPIGMENTOS, desde a década de 1970. Contudo, os grandes projetos possuem alto potencial de impacto negativo no meio ambiente, seja ele físico, biológico ou socioeconômico. Além disso, são responsáveis por intensos fluxos migratórios, que são desproporcionais ao planejamento urbano, potencializando os problemas sociais e a fragmentação do território (SANTOS, 2015).

Outro fato relevante a ser considerado diz respeito às áreas de vegetação, as quais estão sujeitas aos focos de calor e a ameaça de alastramento para novas áreas urbanas, enquanto que os padrões produtivos da mineração e outras atividades que fazem parte do complexo industrial de Barcarena apresentam riscos de desastres para a população e todo o entorno (CARMO; COSTA, 2016).

Então, em meio a tantos desastres ambientais, a proteção ao meio ambiente está se tornando, cada vez mais, uma questão de necessidade. Com a evidente situação, considera-se necessárias as tomadas de decisões, cuja prioridade está na busca de formas protecionistas que sejam viáveis ao ponto de vista socioambiental, que não limitem o desenvolvimento e que proporcionem o bem-estar coletivo (SOUSA, 2014). 
Diante do exposto, o CAR surgiu como um instrumento para a regularização ambiental das propriedades rurais. Em 2012, foi legalizado, nacionalmente, pelo "Novo Código Florestal", tornando-se um componente obrigatório. O código tem como objetivo estabelecer normas gerais sobre a proteção da vegetação, áreas de Preservação Permanente e as áreas de Reserva Legal, a exploração florestal, o suprimento de matéria-prima florestal, o controle da origem dos produtos florestais, o controle e prevenção dos incêndios florestais, prevê instrumentos econômicos e financeiros para o alcance de seus objetivos (PALMEIRAS, 2015a).

As geotecnologias usadas como subsídio para o CAR, são um conjunto de tecnologias destinadas a coleta, o processamento, a análise e a oferta de informações com referência geográfica, as quais integram soluções em hardware e software como poderosas ferramentas para tomadas de decisões (ROSA, 2005). Dentre essas ferramentas, cita-se o Sensoriamento Remoto, o qual, conforme Rosa (2009), permite a aquisição de uma grande quantidade de dados, sendo esses confiáveis, rápidos e repetitivos. Esses requisitos são essenciais, pois fornecem informações de grande importância para o levantamento, mapeamento e utilização das informações de uso e ocupação da terra em um determinado local.

Ademais, o uso das geotecnologias auxilia na interpolação dos dados reais extraídos em bases cartográficas, ou trabalhos a campo, processados em softwares que aceleram o encontro dos resultados, podendo ser analisados e interpretados através de mapas temáticos, ricos em detalhes. Desse modo, o uso dessas torna-se imprescindível nos estudos ambientais, pois permite uma abordagem complexa e integradora das relações entre natureza e sociedade, fundamental para a realização das práticas eficientes na gestão ambiental (PALMEIRAS, 2015b).

Almeida (2005), afirma o QGIS como um software simples e intuitivo, graças à moderna interface gráfica. O programa, dada as suas peculiaridades, tem destinado-se com grande relevância no que diz respeito ao mapeamento de áreas e auxílio no controle ambiental e espacial de forma geral. É necessário destacar que isso tudo tornou-se possível graças aos aparatos tecnológicos que se tem conhecimento e acesso, atualmente.

\section{Metodologia}

\section{Área de estudo}

O município de Barcarena do Estado do Pará, localiza-se no norte brasileiro, a uma latitude $01^{\circ} 30^{\prime} 21^{\prime \prime}$ sul e longitude $48^{\circ} 37^{\prime} 33^{\prime \prime}$ oeste. Estende- se por $1310,3 \mathrm{~km}^{2}$, com densidade 
demográfica de 76,2 habitantes por $\mathrm{km}^{2}$. Vizinho dos municípios de Belém, Abaetetuba e Ponta de Pedras, pertencente à mesorregião Metropolitana de Belém (Mapa 1).

Mapa 1 - Representação do município de Barcarena, no estado do Pará.

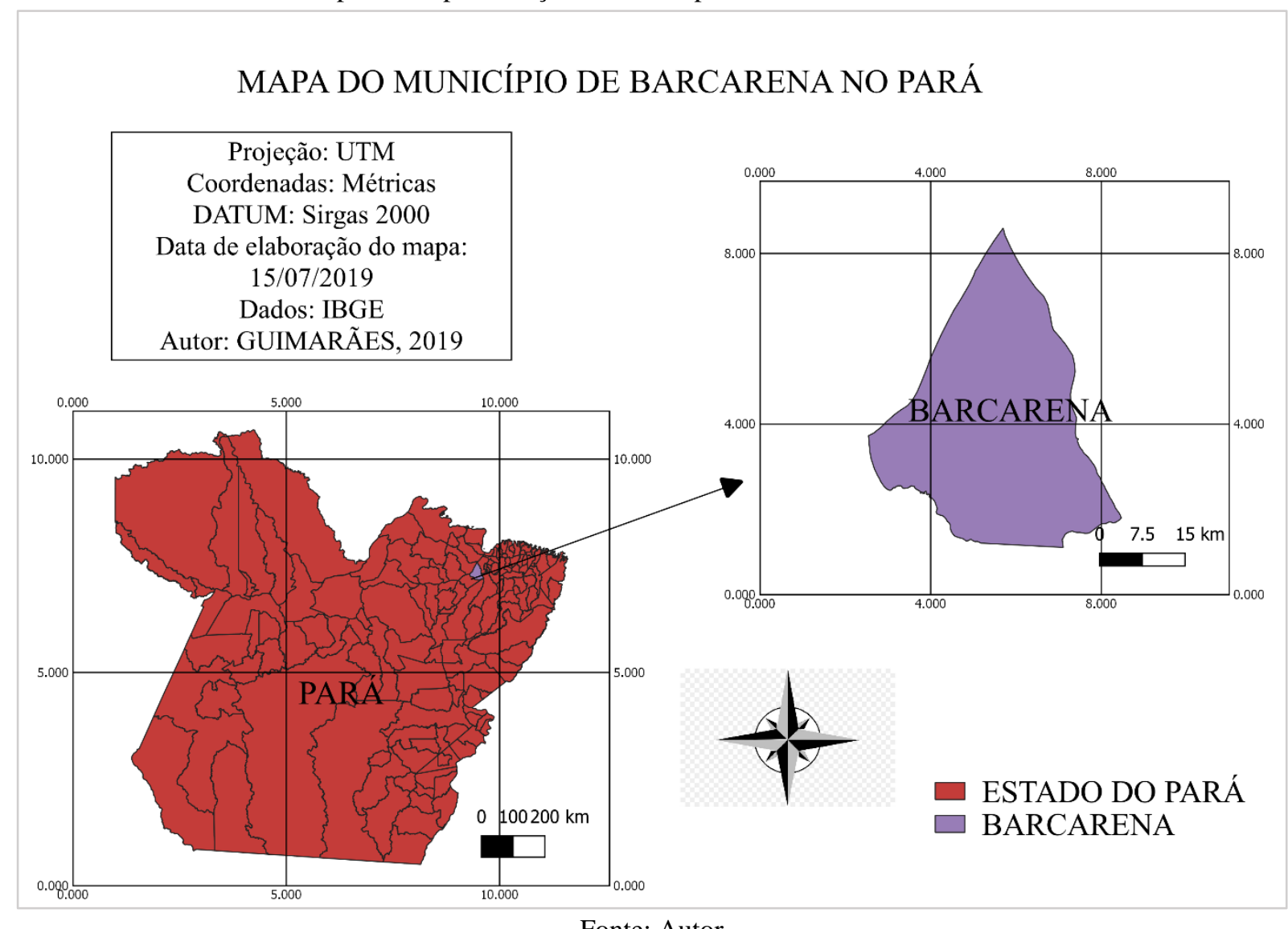

Fonte: Autor

\section{Obtenção dos dados}

No site do IBGE, na área de geociências, fez-se os downloads da carta imagem dos limites municipais do brasil e da região norte. São imagens aéreas e orbitais, mapas, malhas, além de conteúdos da INDE, atlas e arquivos Google Earth e entre outros (Figura 1). Após essa etapa, inseriu-se os shapefiles no QGIS para a criação do mapa de localização. 
Figura 1 - Downloads das malhas municipais do Brasil

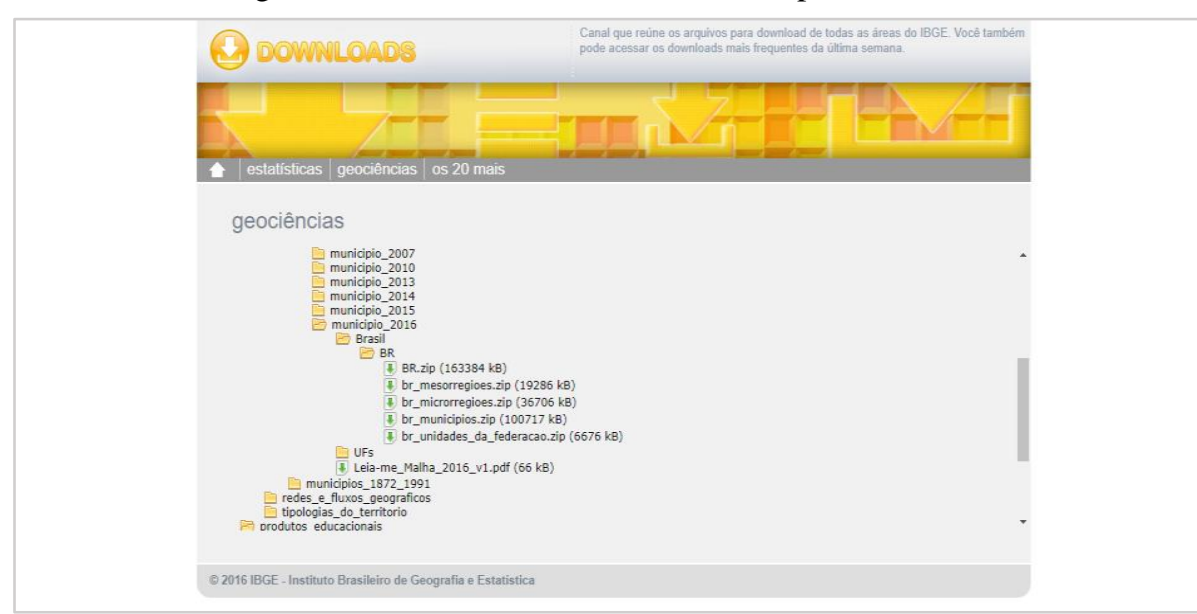

Fonte: Autor

Os dados são do tipo shapefiles, que é um formato de arquivo digital que representa uma feição ou elemento gráfico, obtendo todas as informações dos imóveis rurais do município de Barcarena. Foram usados os shapes da área do imóvel, área de preservação permanente, área de reserva legal, cobertura do solo, área de pousio, área topo de morro, área consolidada, hidrografia, manguezal, uso restrito e vegetação nativa, servidão administrativa e entre outras. A princípio todas as camadas foram criadas no programa QGIS e depois marcadas para uma visualização geral de toda área do município contendo todos os imóveis rurais (Figura 2).

Figura 2 - Inserção de camadas no programa QGIS

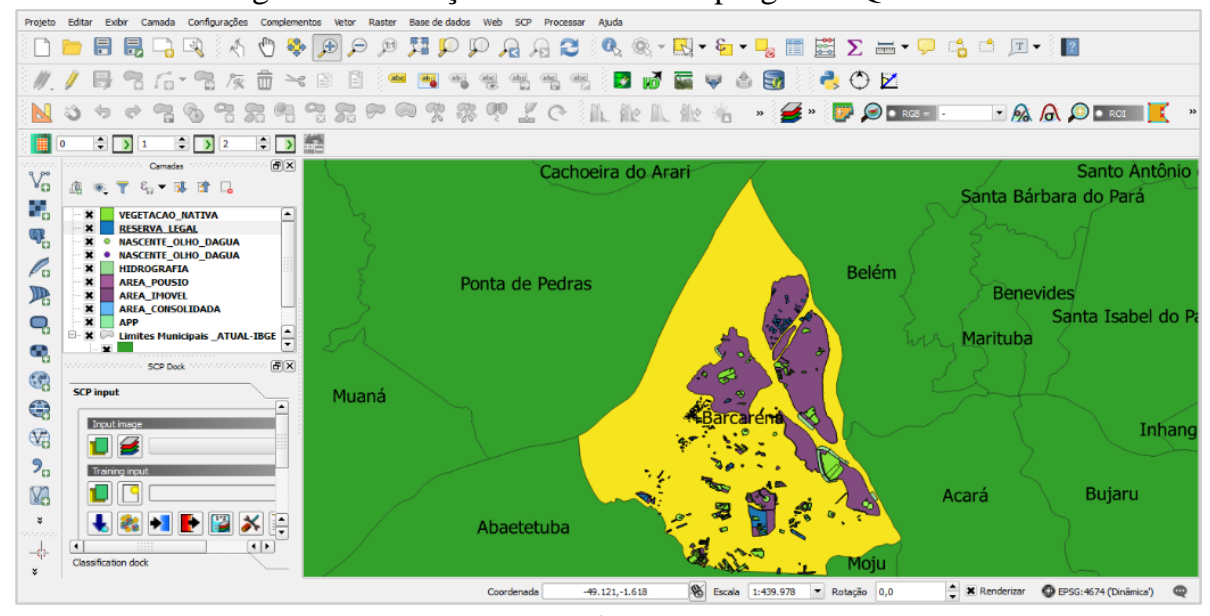

Fonte: Autor

Em relação aos dados para a consolidação efetiva do CAR, foram obtidos via internet através do Sistema Nacional de Cadastro Ambiental Rural - SICAR criado por meio do Decreto $\mathrm{n}^{\circ}$ 7.830/2012 e definido como sistema eletrônico de âmbito nacional destinado à integração e ao gerenciamento de informações ambientais dos imóveis rurais de todo o País. 


\section{Critérios para Análise dos Dados}

Depois da obtenção dos dados, junto ao SICAR, fez-se a descompactação dos shapefiles da área do imóvel, servidão administrativa, reserva legal, nascentes de olho d’água, hidrografia, área de pousio, área consolidada, área de preservação permanente e limites municipais. Em seguida, foram inseridos no programa QGIS.

Posteriormente, adicionou-se todos os shapes no programa e, logo em seguida, marcouse apenas o shapefile da área do imóvel e do limite dos municípios para uma melhor visualização dos imóveis rurais cadastrados no CAR (Figura 3).

Figura 3 - Área do imóvel estudado (Fazenda Acapu)

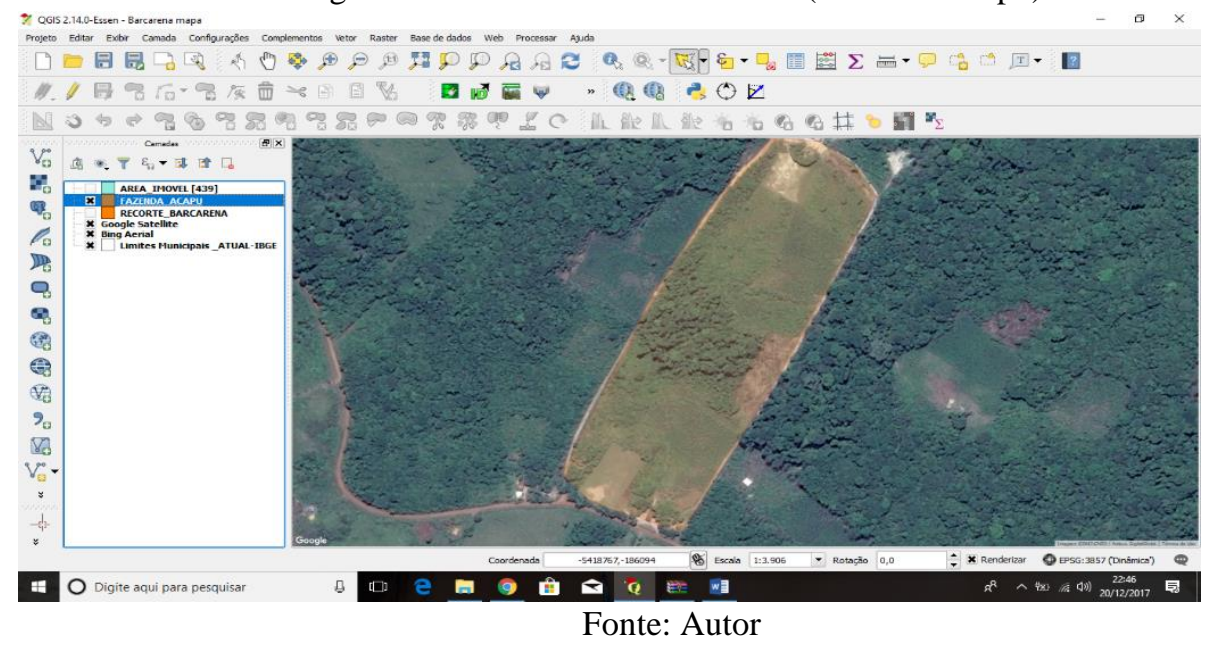

$\mathrm{Na}$ figura abaixo mostra-se as camadas já inseridas no programa, com destaque para as áreas de reserva legal, APP, área do imóvel e limite dos municípios (Figura 4).

Figura 4 - Camadas marcadas

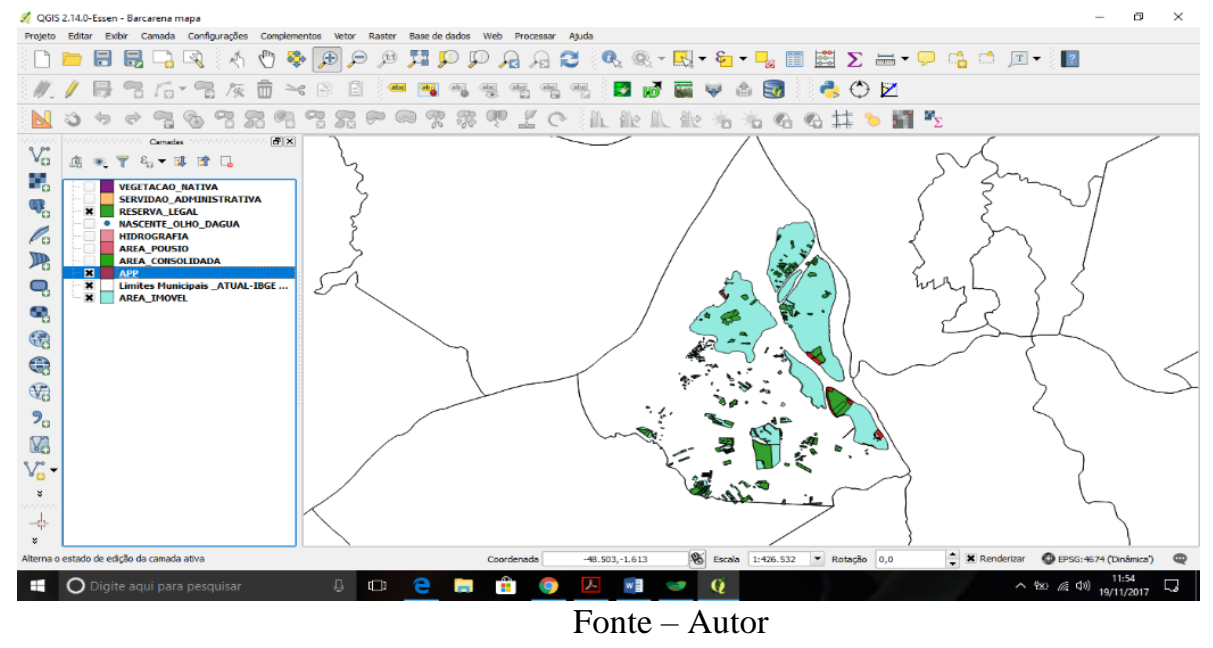

O módulo de Cadastro Ambiental Rural 
O procedimento para a realização do Cadastro Ambiental Rural está disponível para ser baixado no site do CAR (www.car.gov.br), e instalado na máquina de acesso do cadastrador (Figura 5).

Figura 5 - Primeiro passo para baixar o módulo do CAR



Fonte: Autor

\section{Inscrição no CAR}

Para iniciar a inscrição do imóvel é necessário baixar a imagem do município (Figura 6). Após a efetivação do download das imagens, não há mais a necessidade de acesso à internet para continuar o Cadastro. Para iniciar o Cadastro, selecione o item "cadastrar" na porção superior da tela (Figura 7). Então, abrirá a tela "cadastro de imóveis".

Figura 6 - Processo de download da imagem do município, no site do CAR



Fonte: Autor 
Figura 7 - Representação dos primeiros passos para execução do cadastro no site



Fonte: Autor

$\mathrm{Na}$ (Figura 8), mostra-se o próximo passo após a consolidação do cadastro do imóvel. Aparecerá a lista de imóveis já cadastrados, no caso do trabalho, apenas o município de Barcarena está em cadastramento, com os seus dados principais, podendo os mesmos serem retificados no item "Retificar um cadastro", ou pode-se iniciar um novo Cadastro no item “cadastrar novo imóvel”, ao acessar o item "cadastrar".

Figura 8 - Selecionando o tipo de imóvel a ser usado

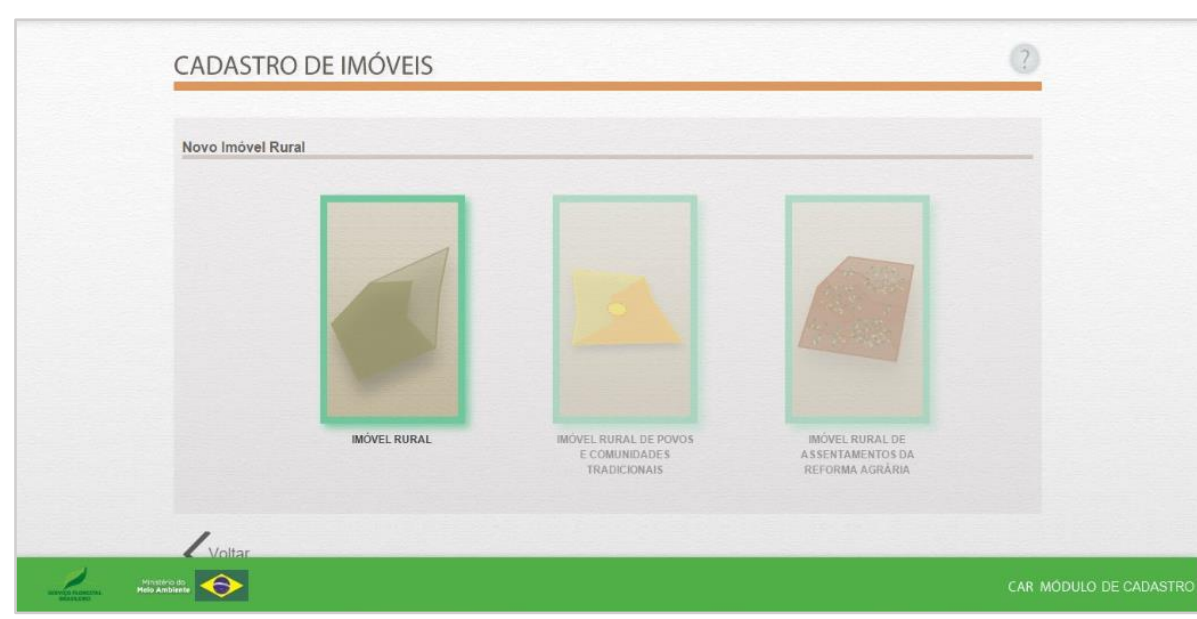

Fonte: Autor

\section{Cadastrante}

O produtor ou cadastrante deve baixar o módulo referente ao seu estado. Após efetuar o download e a instalação, o cadastrante deve baixar, também, as imagens de interesse para o local da propriedade. As imagens disponibilizadas pelo módulo de Cadastro deveriam ter até 5 metros de resolução espacial. Na tela inicial do Cadastro além de baixar imagens, o cadastrante 
poderá gravar um Cadastro, enviar o Cadastro ao módulo, ou ter acesso a retificação (Figura 9).

O primeiro item a ser cadastrado remete à pessoa que está fazendo o preenchimento do cadastro (Figura 10). Nesta tela é preenchido com o CPF, Data de Nascimento, e Nome do cadastrante e de sua Mãe. Os campos com o símbolo * são de preenchimento obrigatório. Após os dados serem preenchidos, selecionar o item "próximo" no canto inferior direito.

Figura 9 - primeiro passo para baixar o modulo do CAR

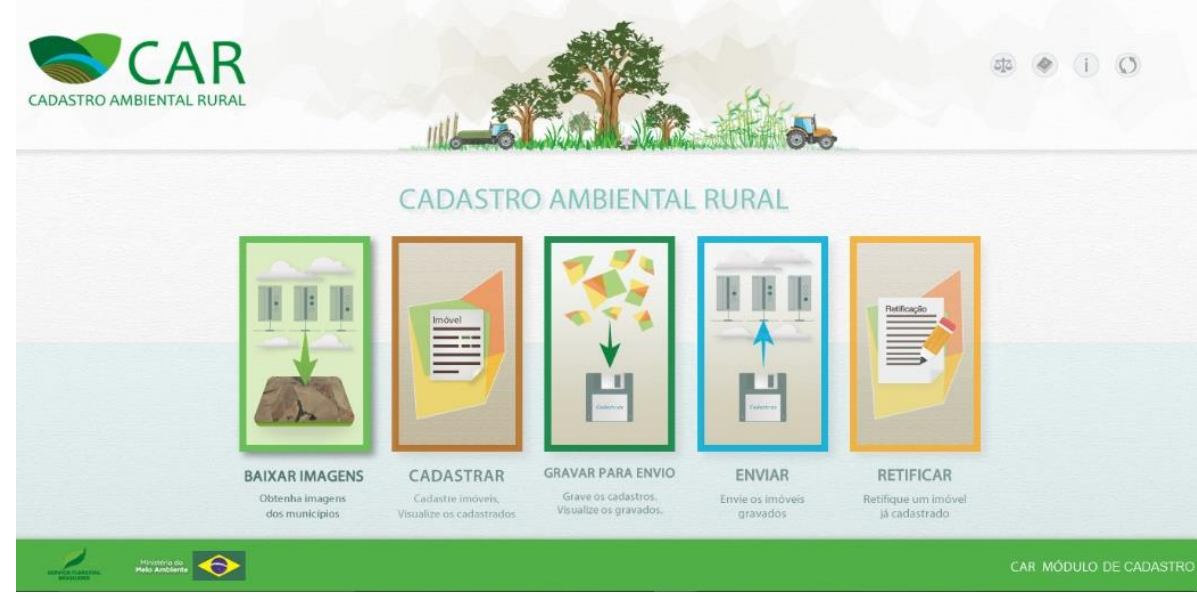

Fonte: Autor

\section{Figura 10 - Cadastrante}



Fonte: Autor

\section{Cadastro do Imóvel}

Nesse momento devem-se incluir os Dados do Imóvel: Nome do Imóvel, UF, Município, CEP (opcional), Descrição de acesso (descrever como chegar à propriedade a partir da cidade mais próxima, incluindo pontos de referência), Zona Rural ou urbana; e os Dados de 
Contato do Imóvel: Endereço/Logradouro, Número, Complemento, Bairro, CEP, UF, Município, E-mail (opcional) e telefone (opcional).

A partir dos Dados de Contato do Imóvel, o órgão Ambiental irá se comunicar com o proprietário caso seja necessário, por isso, deve-se ter o cuidado de preencher os dados corrtamente para não haver desencontros. Após o preenchimento dos dados, seleciona-se o item "próximo" no canto inferior direito da tela, para dar prosseguimento (Figura 11).

Figura 11: Imóvel

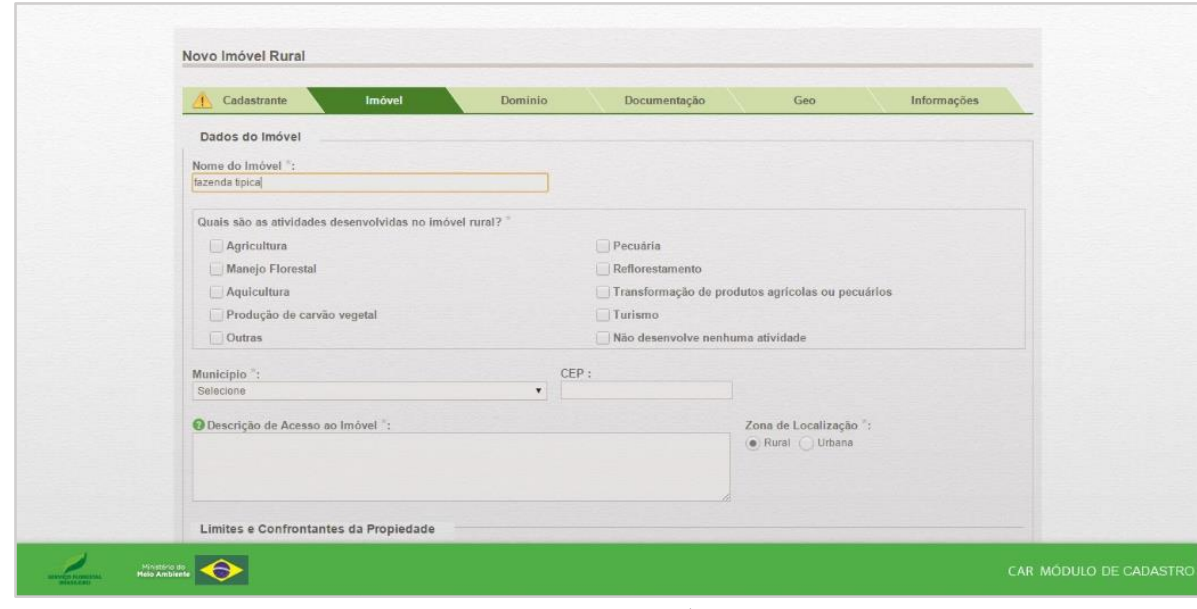

Fonte: Autor

\section{Cadastro de Domínio}

Os dados de domínio referem-se aos dados do proprietário ou posseiro do imóvel, que pode ser um ou mais produtores. Caso tenha mais de um proprietário, todos devem ser cadastrados (Figura 12).

Selecionar Pessoa Física ou Pessoa Jurídica e incluir o CPF ou CNPJ, Data de Nascimento, Nome pessoal e da Mãe de cada proprietário. Posteriormente, seleciona-se o botão "adicionar". Abaixo, irão aparecer os proprietários/possuidores adicionados. Após os dados serem preenchidos selecionar o item "próximo" no canto inferior direito. 
Figura 12: Domínio

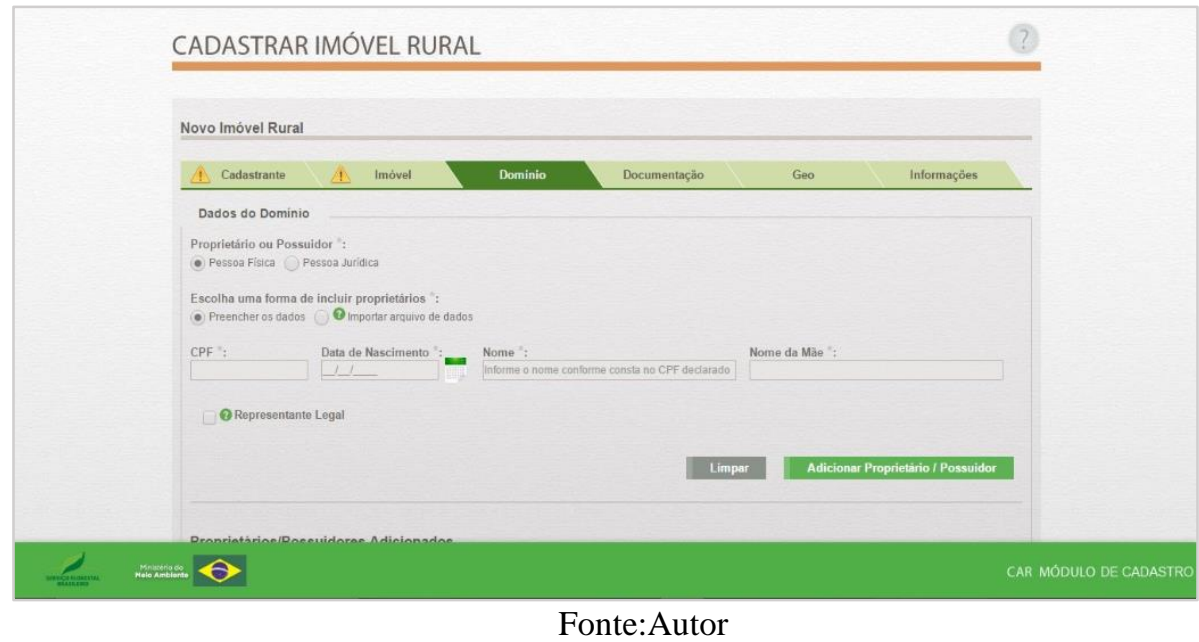

\section{Documentação}

Nesta tela (Figura 13), devem-se inserir os dados dos documentos que comprovam o domínio ou posse da propriedade. Um imóvel pode ser composto por uma ou mais matrículas somadas às áreas de posse ou não. A cada documento adicionado deve-se cadastrar os proprietários do imóvel e selecionar o botão verde com sinal de + para cada proprietário adicionado e, após isso, clicar no botão verde "adicionar".

Abaixo, no item "documentos adicionados", aparecerá a lista de documentos que compõem a propriedade e a área total da propriedade. Após os dados serem preenchidos, selecionar o item "próximo" no canto inferior direito.

Figura 13 - Documentação



Fonte: Autor

GEO

Na tela do GEO (Figura 14), o cadastrante irá delimitar o imóvel e suas características. Ao abri-la, mostra-se a imagem do município que foi cadastrada. Na porção superior da tela, o 
cadastrante selecionará os temas, item por item, para serem inseridos os shapefiles que foram vetorizados no QGIS: ÁREA DO IMÓVEL, SERVIDÃO ADMINISTRATIVA, APP/USO RESTRITO, COBERTURA DO SOLO, RESERVA LEGAL E ÁREA FINAL, sendo que o primeiro tema a ser inserido foi a área do imóvel, onde a mesma delimitará o perímetro total da propriedade. Para auxiliar a inclusão dos temas descritos acima, foi usado o botão inserir camadas shapefile.

Figura 14: Etapa Geo

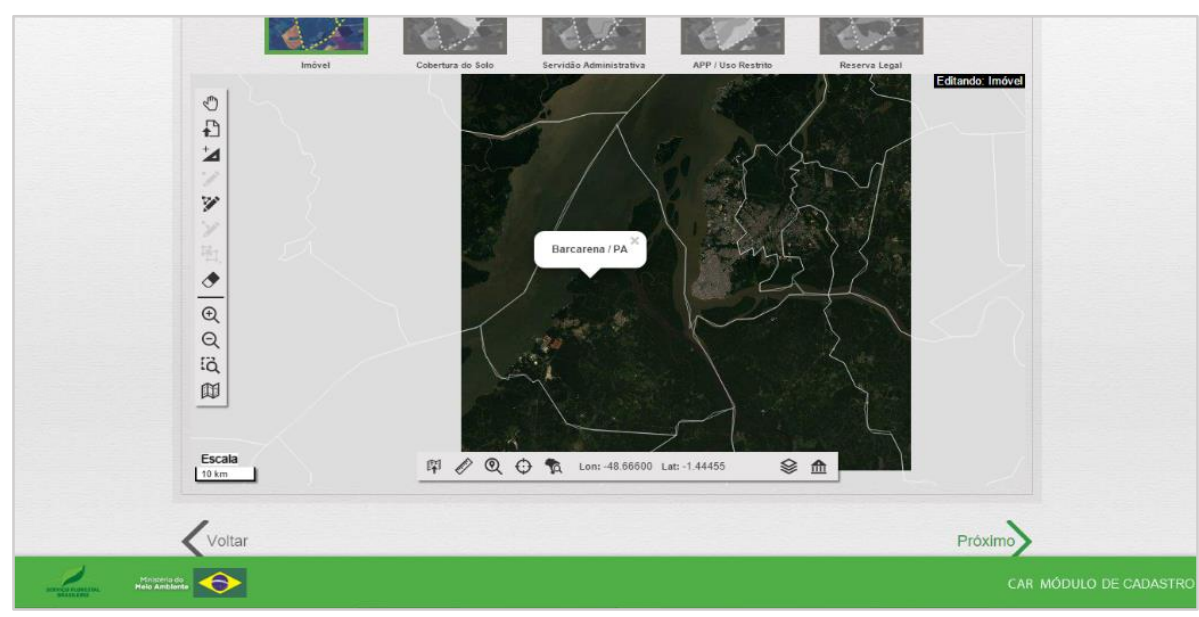

Fonte: Autor

\section{Resultados e Discussão}

Todos os procedimentos essenciais para o Cadastro Ambiental Rural, propriamente dito, foram executados conforme o passo a passo. Por conseguinte, após a inserção dos dados baixados no mesmo local do cadastro, no software QGIS fez-se o mapeamento e delimitação territorial, via processamento digital.

A problemática de grande relevância nesse contexto está relacionada com o mau manuseio das ferramentas disponíveis, uma vez que qualquer pessoa, com ou sem experiência, pode fazer o cadastro, isso pode acarretar em problemas na limitação territorial ao consolidar o CAR. Conforme o trabalho desenvolvido pela Agência Pública (2016), há evidências e inconsistências da base de dados do CAR. Em parte, isso pode ser explicado devido a liberdade de acesso e à falta de apoio técnico nos procedimentos. Ainda mais, acrescentam que dos 150 mil registros do CAR paraense, 108 mil apresentaram áreas sobrepostas com outros imóveis rurais chegando a 240 mil áreas de sobreposição, totalizando em mais de 14 milhões de hectares. Essas áreas sobrepostas, muitas vezes, coincidem com áreas protegidas, como: terras indígenas, Unidades de Conservação de Proteção Integral, entre outras. 
O problema relacionado a sobreposição de terras dificulta, posteriormente, na execução do mapeamento da área. Então, para o manuseio tanto do software QGIS, como do Cadastro Ambiental Rural, faz-se necessária a presença de profissionais qualificados para a manipulação desses componentes, seja para a própria consolidação, ou até mesmo para prestar orientações.

\section{Conclusões}

Em síntese, concluiu-se o Cadastro Ambiental Rural por meio da utilização do software QGIS, o qual mostrou-se eficiente no ponto de vista econômico, pois é um programa gratuito e, também, devido ao seu fácil manuseio. Todavia, destaca-se que por mais simples que sejam os procedimentos, há a necessidade de acompanhamento no cadastro e no mapeamento.

\section{Referências}

AGÊNCIA PÚBLICA. As falhas e inconsistências do Cadastro Ambiental Rural. 2016. Disponível em: <http://apublica.org/2016/08/as-falhas-e-inconsistencias-do-cadastroambiental-rural/>. Acesso em: 15 de jun. 2019.

ALMEIDA, R. P. O.; SÁNCHEZ, L. E. Revegetação de áreas de mineração: critérios de monitoramento e avaliação do desempenho. R. Árvore, Viçosa-MG, v.29, n.1, p.47-54, 2005.

ANTUNES, M. A. H; DEBIASI, P.; SIQUEIRA, J. C. dos S. Avaliação espectral e geométrica das imagens RapidEye e seu potencial para o mapeamento e monitoramento agrícola e ambiental. Revista Brasileira de Cartografia, v. 66, n. 1, p. 105-113, 2014.

CÂMARA， G.; DAVIS， C. Fundamentos de geoprocessamento. Livro on-line: www.dpi.inpe.br, 1996.

CARMO, M.B.; COSTA, S.M. F. Os paradoxos entre os urbanos no município de Barcarena, Pará. Revista Brasileira de Gestão Urbana (Brazilian Journal of Urban Management), v. 8, n. 3, p. 291-305, set./dez 2016.

COELHO, N. C. M.; MONTEIRO, A. M.; SANTOS, C. I. Políticas públicas, corredores de exportação, modernização portuária, industrialização e impactos territoriais e ambientais no município de Barcarena, Pará. Novos Cadernos NAEA, v. 11, n. 1, p. 141-178, jun. 2004. MORETTI, G; ZUMBACH, L. Cadastro Ambiental Rural (Car) - Nasce a Identidade do Imóvel Rural, 1. ed. Curitiba, 2015.

NASCIMENTO, P. A. M. do. Gestão ambiental em área de risco no município de Barcarena/Pará. Dissertação de Mestrado, NAEA - UFPA. Belém, 2012. p. 35-36.

OLIANI, L. O.; PAIVA, C.; ANTUNES, A. F. B. Utilização de softwares livres de geoprocessamento para gestão urbana em municípios de pequeno e médio porte. IV Simpósio Brasileiro de Ciências Geodésicas e Tecnologias da Geoinformação, Recife: PE, 06- 09 de maio de 2012, p. 001 - 008, 2012. 
PALMEIRAS, L. F.G. Geoprocessamento aplicado ao cadastro ambiental rural em são Pedro do Sul - RS. Relatório final de estágio curricular obrigatório, 2015.

ROSA, R. Introdução ao Geoprocessamento. Universidade Federal de Uberlândia, 2013, p. 60 .

ROSA, R. Introdução ao Sensoriamento Remoto. 7 ed. Uberlândia: EDUFU, 2009. 262 p.

ROSA, Roberto. Geotecnologias na geografia aplicada. Revista do Departamento de Geografia, v. 16, p. 81-90, 2005.

SANTOS, S. S. M. Capacidade Institucional, gestão ambiental descentralizada e sustentabilidade: o caso de Barcarena (PA). Dissertação de Mestrado - Programa de Pósgraduação em Gestão dos Recursos Naturais e Desenvolvimento Local na Amazônia, Belém, 2015.

SOUSA, A. E. Estudo da viabilidade e da implementação do cadastro técnico multifinalitário com o emprego do software livre quantum gis: São Tiago - MG. Trabalho de conclusão de curso apresentado como requisito parcial à obtenção do grau de Especialista em Geoprocessamento, Instituto de Geociências: UFMG, Belo Horizonte, 2014.

TEIXEIRA NETO, E. S. de F.; MELO, J. A. M. de. Cadastro ambiental rural, CAR - um estudo sobre as principais dificuldades relacionadas a sua implantação. Negócios em Projeção, v. 7, n. 2 , p. $54-68,2016$. 